\section{Part 2}

5. The reaction kinetics of the hydrolytic decomposition of $\mathrm{G}_{2} \mathrm{~S}_{2}$ and cystine in the presence of an excess of silver nitrate were studied under various conditions. The reactions were classified into three main types.

6. Acetate was shown to catalyse the reaction of cystine and, to a much lesser extent, that of $G_{2} S_{2}$. Similarly, barbitone inhibited the cystine reaction completely, but that of $\mathrm{G}_{2} \mathrm{~S}_{2}$ only slightly.

7. In the presence of $\mathrm{GSH}$ and $\mathrm{G}_{2} \mathrm{~S}_{2}$, cystine was shown to behave in a manner resembling $\mathrm{G}_{2} \mathrm{~S}_{2}$.

8. Tentative explanations for the three different types of reaction kinetics are put forward.
9. A possible explanation for the greater reactivity of the sulphur in GSH and $\mathrm{G}_{2} \mathrm{~S}_{2}$ as compared with that in cysteine in cystine is given. This involves a hydrogen bond between the sulphur in GSH and $\mathrm{G}_{2} \mathrm{~S}_{2}$ and the $-\mathrm{NH}_{3}{ }^{+}$group of the glutamyl radical.

My thanks are due to Dr A. G. Ogston for much helpful advice, and to Dr R. B. Fisher for the gift of glutathione.

Correction. Subsequent work has disclosed an impurity in the $\alpha$-picoline used in Part 2 of this work. The cystinesilver nitrate reaction carried out with purified $\alpha$-picoline at $\mathrm{pH7.0}$ is Type II and not Type III. Curve $C$ in Fig. 7 becomes intermediate between curves $A$ and $D$. No other results are affected. Details will be given in a later publication.

\title{
REFERENCES
}

Benesch, R. \& Benesch, R. E. (1948). Arch. Biochem. 19, 35. Blackburn, S. \& Challenger, F. (1938). J. chem. Soc. p. 1872. Brand, E. \& Sandberg, M. (1926). J. biol. Chem. 70, 381. Cannan, R. K. \& Knight, B. C. J. G. (1927). Biochem. J. 21, 1384.

Challenger, F. \& Rawlings, A. A. (1937). J.chem. Soc. p. 868.

Clarke, H. T. (1932). J. biol. Chem. 97, 235.

Dixon, M. \& Quastel, J. H. (1923). J. chem. Soc. p. 2943.

Fromm, E. (1908). Ber. dtsch. chem. Ges. 41, 3403.

Hass, K. \& Jellinek, K. (1932). Z. phys. Chem. 162, 153.

Heatley, N. G. (1939). Mikrochemie, 26, 147.

Hopkins, F. G. (1929). J. biol. Chem. 84, 269.

Hopkins, G. \& Hunter, L. (1942). J. chem. Soc. p. 638.

Kolthoff, I. M. \& Harris, W. E. (1946). Industr. Engng Chem. (Anal. ed.). 18, 161.

Lavine, T. F. (1936). J. biol. Chem. 113, 583.

Lavine, T. F. (1937). J. biol. Chem. 117, 309.
MacInnes, D. A. \& Dole, M. (1929). Industr. Engng Chem. (Anal. ed.). 1, 57.

Michaelis, L. \& Flexner, L. B. (1928). J. biol. Chem. 79, 689. Pirie, N. W. (1930). Biochem. J. 24, 51.

Pirie, N. W. (1931). Biochem. J. 25, 614.

Pirie, N. W. \& Pinhey, K. G. (1929). J. biol. Chem. 84, 321.

Ruka, R. \& Willard, J. E. (1949). J. phys. colloid Chem. 53, 351.

Ryklan, L. R. \& Schmidt, C. L. A. (1944). Univ. Calif. Publ. Physiol. 8, 257.

Schiller, R. \& Otto, R. (1876). Ber. dtsch. chem. Ges. 9, 1637.

Schöberl, A. \& Hornung, T. (1938). Liebigs Ann. 534, 210.

Schöberl, A. \& Ludwig, E. (1937). Ber. dtsch. chem. Ges. 70, 1422.

Vickery, H. G. \& Leavenworth, C. S. (1930). J. biol. Chem. 86, 129.

\section{Comparative Studies of 'Bile Salts'}

\section{PRELIMINARY SURVEY}

\author{
By G. A. D. HASLEWOOD AND VERYAN WOOTTON \\ Guy's Hospital Medical School, London, S.E. 1
}

(Received 3 April 1950)

Bile is apparently produced by all vertebrates, and the 'bile salts' might perhaps be described as physiologically the most important constituent. In the absence of complete data and a knowledge of the problems of digestion and absorption to be solved by each species, it is hardly possible at present to speculate profitably about the efficiency (for digestion and absorption) of different biles. It is, however, of some interest that the nature of the bile salts is by no means constant, but sometimes shows considerable differences as between species and species. Many of these differences are, chemically, considerable; they do not appear to be dependent on temporary variations of environment, but are apparently characteristic of, and invariable in, a species.
It seems, therefore, that we may have in the chemical nature of bile salts a character which will be of some value as a clue to species characterization, and which might even be an aid in the study of evolutionary history.

Any such possibility can only be explored after a wide comparative survey of the occurrence of different bile salts. Such a survey appears to have been begun by Japanese workers between about 1920 and 1941, largely as an attempt to find and identify intermediates in the assumed oxidation of cholesterol to the bile acids. A comprehensive collection of results does not appear in the literature: we have attempted to fill this gap in Tables 1-4. To avoid multiple references these tables refer to collections of data already made by Sobotka (1937) and 
Fieser \& Fieser (1949), but their compilation has involved in addition extensive search in the literature. In the tables, results as claimed by authors are given; some of these claims are untenable and are critically discussed later. Of the six species of birds examined, all contained chenodeoxycholic acid, and in three species small amounts of cholic acid were detected (Sobotka, 1937; Sobotka \& Bloch, 1943). We have also included the results of our own preliminary examinations of the bile salts of a number of species.

We have tried to work out methods for the characterization of bile salts which will be generally applicable to small quantities. In the course of our work we have already encountered a number of substances not hitherto described.

Preliminary communications on this work have already appeared (Haslewood \& Wootton, 1950).

\section{METHODS}

General. All melting points are uncorrected. Aluminium oxide was obtained from Hopkin and Williams Ltd. Micro-analyses were done by Drs Weiler and Strauss, Oxford, or by Dr A.T. Macdonald. l.p. = light petroleum (b.p. 40-45 ${ }^{\circ}$. H-test $=$ Hammarsten's hydrochloric acid test (Haslewood, 1943). $20 \%$ chromic acid refers to a solution made by dissolving chromium trioxide $(20 \mathrm{~g}$.) in the minimal amount of water and making to $100 \mathrm{ml}$. with acetic acid. Whenever cholic acid, ethyl cholate, dehydrocholic acid or ethyl dehydrocholate were obtained as purified crystals, mixed melting points with authentic samples were determined and showed no depression.

\section{Collection of bile}

Except in the special cases mentioned, bile was collected by putting the gall-bladders, as soon as possible after the death of the animal, into ethanol in which they were left until working-up began.

Horse bile. (From an account supplied by H. D. Mills.) As soon as possible after the animal was shot, the abdomen was opened along the linea alba and the bile duct located. A syringe was inserted into this, and bile, if any, aspirated. The yield was very variable, frequently nil. The bile was a golden-brown colour; its volume was measured, and it was poured into 2-3 vol. of ethanol as soon as possible. In the horse, the common bile duct acts as a reservoir (Mills, 1949), and there is a large amount of constantly flowing dilute bile. Except when the choledochoduodenal junction is occluded, it is unlikely that the bile duct is ever full to capacity when the animal is alive. This method of getting bile was unsatisfactory; enough bile for a more complete investigation would require a very large number of animals or some other technique.

Whale bile. (a) Balaenoptera physalus. The bile was collected by Dr M. Begg of the 'Discovery' expedition. As soon as the whale, a sexually mature male (perhaps 10 years old, $22.1 \mathrm{~m}$. in length), was cut up, the bile, which was found in the third stomach or possibly the duodenum, was collected and mixed with 1-2 vol. of ethanol. The total quantity of bile was approximately 31 . ; the ethanolic mixture was kept at about $0^{\circ}$ during the voyage. It was further diluted with 2 vol. of ethanol and worked up as described. (b) Balaenoptera sibbaldi. Unpreserved bile $(50 \mathrm{ml}$.) was received; we have no information about its collection.

\section{General methods for characterization of bile salts}

The bile was liberated, if necessary, by cutting up and grinding the gall-bladders in a mortar: this material was then extracted with successive quantities of ethanol until fresh extracts were colourless. Further ethanol was added in all cases, until precipitation of mucin, etc., was apparently complete. The resulting bile-salt solution was filtered and evaporated to dryness, finally under reduced pressure, transferred to a dish with fresh ethanol and water, again evaporated and lastly dried over sulphuric acid in a vacuum desiccator. Such preparations were more or less hygroscopic and are referred to in the text as crude bile salts. The weights given for yields of bile salt are those found immediately after removal from a desiccator.

Preliminary purification (White, 1929). The bile salts ( $n$ g.) were dissolved in a little water in a dish, decolorizing charcoal $(0.5 n$ g.) was stirred in and $5 \mathrm{~N}$-sodium hydroxide was added until a spot test just gave a pink colour with phenolphthalein. The whole was evaporated to dryness on a water bath at about $70^{\circ}$ and the residue was extracted with ethanol in a Soxhlet apparatus until the fresh extract was colourless. The filtered extract was evaporated and the bile salts ('purified') obtained as before.

Treatment of conjugated bile salts ('crude' and ' $p u r i f i e d ')$. An attempt was made to separate these by absorption chromatography on aluminium oxide with $n$-butanol, ethanol and methanol. It was found that whereas the sulphur-containing (tauro-) acids were readily eluted as the sodium salts, a part of the glycine-containing acids (glyco-acids) was much more difficult to elute from the column. It was therefore thought possible that use might be made of the considerable differences between the dissociation constants of the tauro- and glycoacids (Josephson, 1933) to effect a separation by chromatography. This idea was only imperfectly realized in practice, although we were able to prepare highly purified sodium taurocholate. (Found, on a sample dried to constant weight at $80^{\circ}: \mathrm{S}, 6 \cdot 2$. Calc. for $\mathrm{C}_{26} \mathrm{H}_{44} \mathrm{O}_{7} \mathrm{NSNa}$ : $\mathrm{S}, 6.0 \%$ ) and glycocholic acid (S, nil) from ox bile salts. 
Table 1. Bile salts of fish

(Classification after Sedgwick, 1905.)

Animal

\section{ELASMOBRANCHII}

Squali (5 species)
Raji (2 species)

TELEOSTEI

CLUPEIDaE

Anchovy, (Jap.) Engraulis

Herring, Clupea harengus

SALMONIDAE

Salmon, Salmo milkschisch

Sweetfish, Plecoglossus altivelis

Cyprinidae

Carp, Cyprinus carpio

Goldfish, Carassius auratus

SIIURIDAE

Sheatfish, Silurus

'Gigi' fish, Pelteobagrus nudiceps

Parasilurus asotus

MURAenidae

Eel, (Jap.)

Conger, Conger myriaster

Conger anago

Moray, Muraenesox cinereus

SCOMBRESOCIDAE

Belone

MUamidDaE

Mullet, Mugil cephalus

GaDIDAR

Cod, Gadus morrhua

G. macrocephalus (Jap.)

Theragra cholcogramma

SRRRANIDAE

Stereoleis ishinagi

ScIaENIDAE

'Nibe' fish, Sciaena mitsukuri

SPARIDAT

Sea bream, Pagrosomus major

'Kurodai' fish, Sparus macrocephalus

Siganidae

'Aigo' fish, Siganus fuscescens

ScOMrBRIDAE

Tunny, Thynnus thynnus

Kingfish, Scomberomorus niphonius

'Katuwo' fish, Euthynnus pelamis

Xiphiidae

Swordfish, Xiphias gladius

Carangidae

Amberfish, Seriola

S. quinqueradiata

Pleuronectidae

Plaice, Pleuronectes platessa

Paralicthys olivaceus

GoBIDAE

Periophthalmus cantonensis

Acanthogobius flavianus

ScorpaEnidae

Sebastodes matsubarae

Sebastodes inermis

BAIISTIDAE

Trigger fish, Monacanthus cirrhifer

TETrodontidat

Globe fish, 'Fugu' fish, Tetrodon

porphyleus

'Bari' fish, probably here

'Okaze' fish, Inimicus japonicus,

untraced

'Beisuke' fish, untraced
Compounds in bile

(acids except scymnol)

Scymnol (all species)

Cholic (2 species)

Possibly a $\mathrm{C}_{27}$-acid (1 species)

Cholic; chenodeoxycholic

Acid unspecified

Cholic

Cholic

Cholic

Cholic

Acid unspecified

Cholic; tetrahydroxynorsterocholanic

Cholic; chenodeoxycholic

Cholic

Cholic

Cholic

Cholic

Acid unspecified

Cholic; chenodeoxycholic

Cholic

Cholic

Cholic; chenodeoxycholic

Cholic

Cholic; chenodeoxycholic

Cholic

Cholic; chenodeoxycholic

Cholic; chenodeoxycholic

Cholic

Cholic

Cholic; chenodeoxycholic

Cholic

Cholic

Cholic

Cholic

Cholic; chenodeoxycholic

Cholic; chenodeoxycholic

Cholic; chenodeoxycholic

Cholic; chenodeoxycholic

Cholic; chenodeoxycholic

Cholic; chenodeoxycholic

Cholic; tetrahydroxy acid

Cholic; chenodeoxycholic; tetrahydroxy Cholic; chenodeoxycholic; tetrahydroxy

Cholic; chenodeoxycholic
Conjugate

Sulphate

二

Taurine

Taurine

Taurine

Taurine

Taurine

Taurine

Taurine

Taurine

Taurine

Taurine

Taurine

Taurine

Taurine

Taurine

Taurine

Taurine

Taurine

Taurine

Taurine

Taurine

Taurine

Taurine

Taurine

Taurine

Taurine

Taurine

Taurine

Taurine

Taurine

Taurine

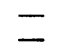

Taurine Taurine

Taurine

Taurine

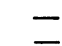

Taurine
References

Fieser \& Fieser (1949)

Oikawa (1925)

Ohta (1939a)

Ohta $(1939 b)$

Sobotka (1937)

Ohta (1939b)

Sobotka (1937)

Sobotka (1937)

Sobotka (1937)

Sobotka (1937)

Ohta (1939b), Isaka \& Azato (1940),

Mabuti (1941b)

Sobotka \& Bloch (1943)

Sobotka (1937)

Sobotka \& Bloch (1943)

Ohta $(1939 b)$

Ohta (1939b)

Sobotka (1937)

Ohta $(1939 b)$

Hammarsten (1904a), present work Ohta $(1939 b)$

Ohta $(1939 b)$

Ohta $(1939 b)$

Ohta $(1939 b)$

Ohta $(1939 b)$

Ohta $(1939 b)$

Ohta (1939b)

Ohta $(1939 b)$

Sobotka (1937)

Ohta (1939b)

Ohta $(1939 b)$

Sobotka (1937)

Ohta (1939b)

Present work

Ohta (1939b)

Tukamoto \& Kataoka (1940)

Tukamoto \& Kataoka (1940)

Ohta $(1939 b)$

Ohta $(1939 b)$

Ohta $(1939 b)$

Isaka \& Azato (1940)

Isaka \& Azato (1940)

Mabuti (1941b)

Ohta $(1939 b)$ 
Table 2. Bile salts of amphibians

(Classification after Smith, 1927.)

\begin{tabular}{|c|c|c|c|}
\hline Animal & Compounds in bile & Conjugate & References \\
\hline $\begin{array}{l}\text { BUFONIDAE } \\
\text { Toad, Bufo vulgaris (Jap.) }\end{array}$ & $\begin{array}{l}\text { Pentahydroxybufostane } \\
\text { Tetrahydroxynorbufostane } \\
\text { Trihydroxybufosterocholenic acid } \\
\text { Trihydroxyisosterocholenic acid } \\
\text { Bufodeoxycholic acid (not } \\
\text { obtained crystalline) }\end{array}$ & Sulphate & Fieser \& Fieser (1949) \\
\hline $\begin{array}{l}\text { RANIDAF } \\
\text { Frog, Rana catesbiana }\end{array}$ & $\begin{array}{l}\text { Tetrahydroxycholane } \\
\text { Trihydroxycholenic acid } \\
\text { Trihydroxybisnorsterocholanic acid }\end{array}$ & $\begin{array}{c}\text { Sulphate } \\
\text { - }\end{array}$ & $\begin{array}{l}\text { Kurauti \& Kazuno (1939) } \\
\text { Mabuti (1941a) }\end{array}$ \\
\hline European frog, Rana temporaria & Polyhydric alcohol(s) & Sulphate & Present work \\
\hline
\end{tabular}

Table 3. Bile salts of reptiles

(Classification after Smith, 1927.)

Compounds in bile

(acids except where stated otherwise) Conjugate

References

Nile monitor, Varanus niloticus

SERPENTES

BOIDAE

Common boa, Constrictor

Western boa, Constrictor

occidentalis

Python, Python tigris

Indian python, Python molurus

African python, Python sebae

Colubridar

Elaphe quadrivirgata

Elaphe carinata

Black and gold tree snake,

Boiga dendrophilus

Indigo snake, Drymarchon

courais couperi

Erapidate

Banded krait, Bungarus

multitinctus

Hallowell's green mamba,

Dendraspis viridis

Yellow cobra, Naja nivea

VIPRRIDAE

Gaboon viper, Bitis gabonica

Crotalnate

Dog faced rattlesnake,

Crotalus terrificus

Timber rattler, Crotalus horridus

Oregon rattler, $C$. oreganus

Crossed viper, Bothrops alternatus

CHELONIA

Testudinidae

European pond tortoise, Emys orbicularis

Chrolonida e

Green edible turtle, Chelone

midas

Soft shelled turtle, Amyda japonica (Trionyx sinensis)
Varanic

- Present work

(

\begin{tabular}{|c|c|c|}
\hline Pythocholic - & Taurine & $\begin{array}{l}\text { Sobotka (1937) } \\
\text { Present work }\end{array}$ \\
\hline $\begin{array}{l}\text { Pythocholic } \\
\text { Pythocholic }\end{array}$ & $\begin{array}{c}\text { Taurine } \\
\text { Taurine } \\
-\end{array}$ & $\begin{array}{l}\text { Sobotka (1937) } \\
\text { Present work } \\
\text { Present work }\end{array}$ \\
\hline $\begin{array}{l}\text { Cholic } \\
\text { Cholic } \\
\text { Cholic }\end{array}$ & $\begin{array}{c}\text { Taurine } \\
- \\
-\end{array}$ & $\begin{array}{l}\text { Sobotka (1937) } \\
\text { Imamura (1940) } \\
\text { Present work }\end{array}$ \\
\hline Cholic & - & Present work \\
\hline Cholic & - & Imamura (1940) \\
\hline Cholic & - & Present work \\
\hline Cholic & - & Present work \\
\hline Unidentified & - & Present work \\
\hline Cholic & - & Deulofeu (1934) \\
\hline $\begin{array}{l}\text { Cholic } \\
\text { Cholic } \\
\text { Cholic }\end{array}$ & E & $\begin{array}{l}\text { Imamura (1940) } \\
\text { Present work } \\
\text { Present work } \\
\text { Deulofeu (1934) }\end{array}$ \\
\hline Trihydroxysterocholanic lactone & - & $\operatorname{Kim}(1939)$ \\
\hline Unidentified acid & - & Present work \\
\hline Tetrahydroxysterocholanic & - & Sobotka (1937) \\
\hline
\end{tabular}


跑

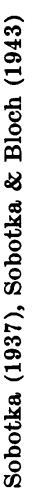
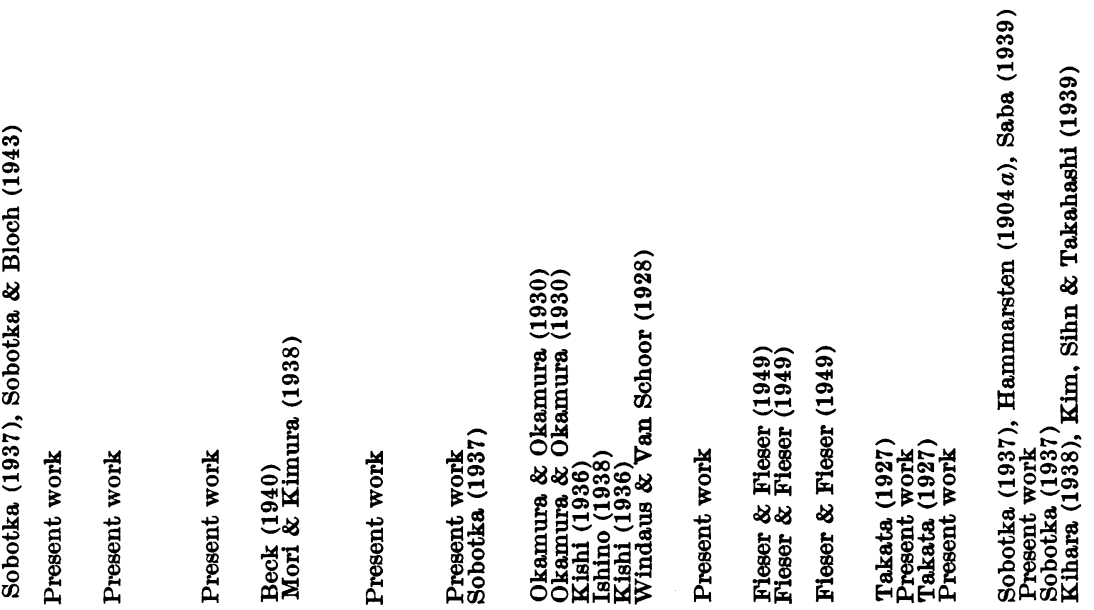

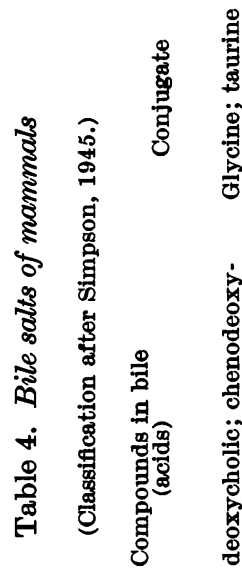

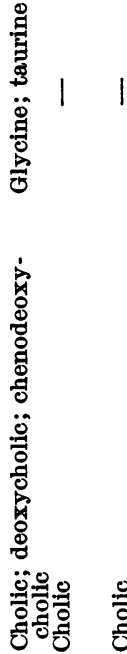

ํㅠㄹ

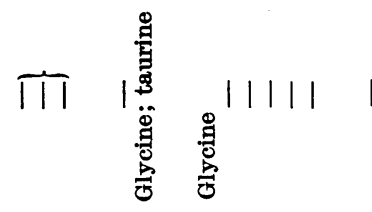

핳월 율

อิి

냉여

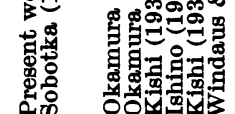

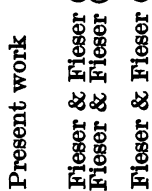

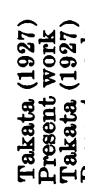

尊

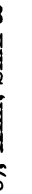


奥虽

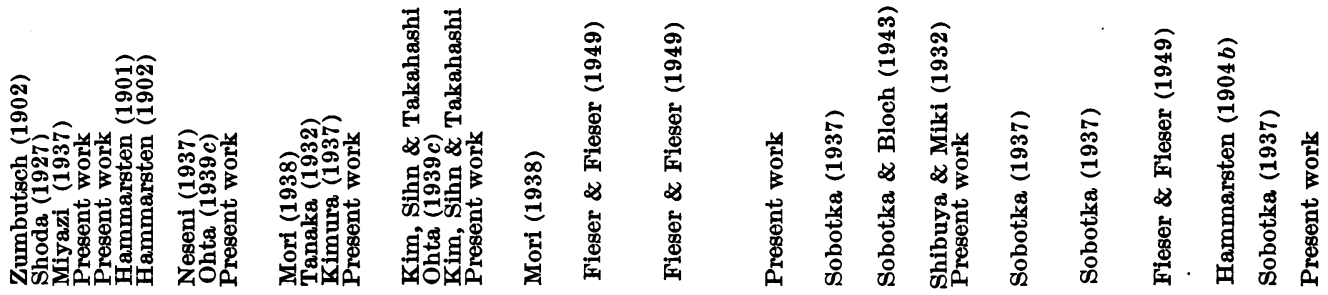

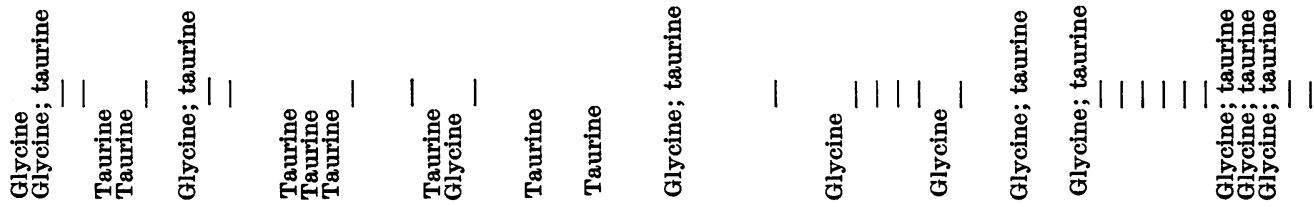
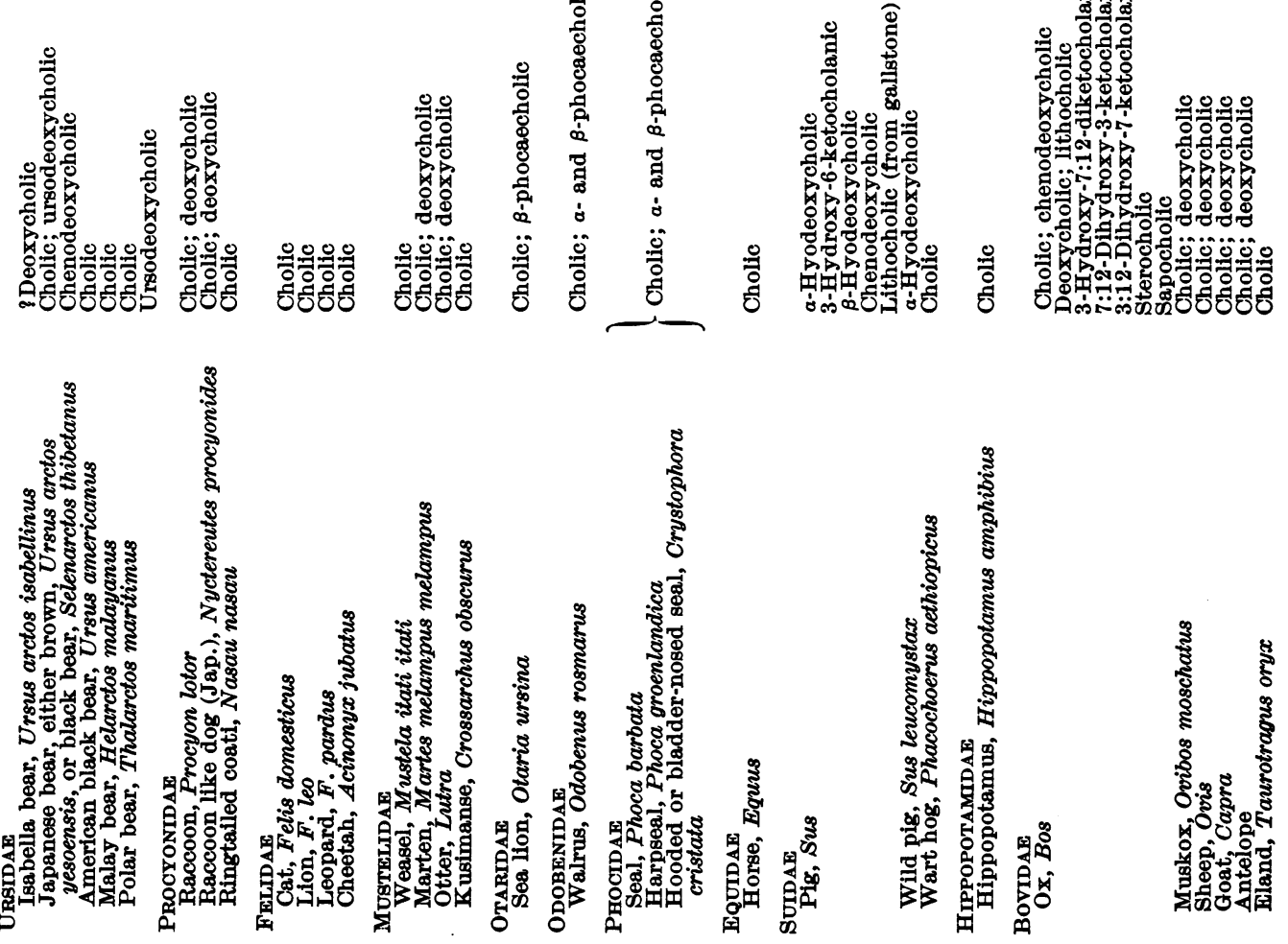
Table 5. Fractionation of acidic products of the hydrolysis of bile salts

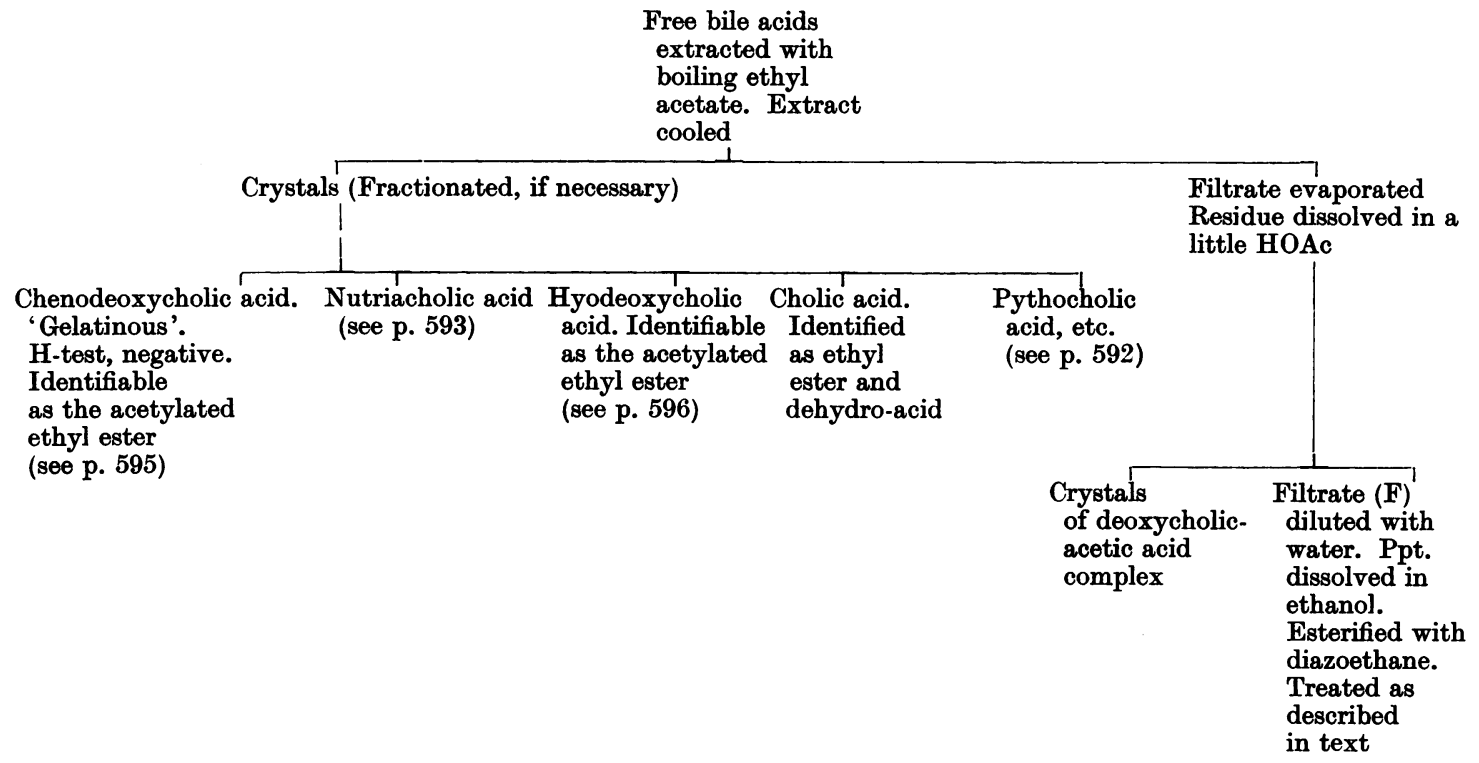

Hydrolysis of bile salts ('crude' and 'purified'). Bile salts ( $1.0 \mathrm{~g}$.) were dissolved as fully as possible at room temperature in $10 \mathrm{ml}$. of $2.5 \mathrm{~N}$-sodium hydroxide and heated in a small bomb at $110-120^{\circ}$ for 5-6 hr. When cool, the contents were washed into a flask, and acidified with dilute hydrochloric acid. Sodium chloride (excess) was added and the precipitate stirred up and left for some hours. The precipitate was collected, well washed with water, dried in vacuo and weighed. If this material was acidic in character, it was treated as shown in Table 5. The identification of crystalline bile acids is described in detail for individual species. The esters from $\mathbf{F}$ (Table 5) were purified on an alumina column. If the hydrolysis yielded mainly neutral material, this was treated as described for individual species.

\section{Species examined}

Order as in Table 1-4.

Gadus morrhua, Cod. Gall-bladders from twenty-four fish gave approx. $16 \cdot 7 \mathrm{~g}$. of very pale coloured bile salts. $1 \mathrm{~g}$. of these on hydrolysis yielded acids which readily crystallized with ethyl acetate, giving cholic acid (0.58 g.) of m.p. 191$194^{\circ}$, raised by one recrystallization from ethyl acetate to 195-197 . The first ethyl acetate mother liquors yielded, on evaporation, a gummy residue weighing $0 \cdot 122 \mathrm{~g}$. Oxidation of the cholic acid gave dehydrocholic acid, m.p. $231-233^{\circ}$ (decomp.).

Pleuronectes platessa, Plaice. Gall-bladders from sixtythree fish gave approx. $4 \cdot 75 \mathrm{~g}$. of nearly colourless bile salts. $1 \mathrm{~g}$. of these gave, after hydrolysis and working up as above, $0.525 \mathrm{~g}$. of cholic acid, m.p. $195-197^{\circ}$, and $0 \cdot 150 \mathrm{~g}$. of gummy acidic material.

Rana temporaria, European frog. Gall-bladders of this species (477) were collected after use of the frogs for teaching and gave $1.88 \mathrm{~g}$. of crystalline solid. This was extracted in a Soxhlet apparatus first with benzene (which removed $20 \mathrm{mg}$. of gummy material) and then with ethanol. Evaporation of the ethanol extract to about $50 \mathrm{ml}$. caused separation of a crystalline solid which was collected after 2 days at $0-5^{\circ}$, washed with cold ethanol and dried. Yield 0.89 g., m.p. 183-184 ${ }^{\circ}, \mathrm{H}$-test, blue. (Found: $\mathrm{H}_{2} \mathrm{O}, 3 \cdot 2,3 \cdot 1 ;$ (after drying): $\mathrm{C}, 57 \cdot 9,57 \cdot 4 ; \mathrm{H}, 8 \cdot 8,9 \cdot 0$. If the residue was $\mathrm{Na}_{2} \mathrm{SO}_{4}, \mathrm{Na}$ was 4.4. Found, on a sample dried to constant weight at $100^{\circ}$ : $\mathrm{S}, 5 \cdot 9,6 \cdot 0$. Found (on $0 \cdot 2$ g.) : $\mathrm{S}, 5 \cdot 9 . \mathrm{C}_{27} \mathrm{H}_{47} \mathrm{O}_{8} \mathrm{SNa}, \mathrm{H}_{2} \mathrm{O}$ requires water, $3.2, \mathrm{~S}, 5.6 \% ; \mathrm{C}_{27} \mathrm{H}_{48} \mathrm{O}_{8} \mathrm{SNa}$ requires $\mathrm{C}, 58 \cdot 5$; $\mathrm{H}, 8.5 ; \mathrm{S}, 5 \cdot 8 ; \mathrm{Na}, 4 \cdot 2 \%$ ). On hydrolysis, this material gave a neutral S-free product which is the object of further study.

Varanus niloticus, Monitor. Bile salts $(4 \cdot 3 \mathrm{~g}$.) were isolated from two gall-bladders; $1 \mathrm{~g}$. of bile salts gave $520 \mathrm{mg}$. of crude bile acids. These would not crystallize from ethyl acetate or ethanol except to give a small amount of material of approx. m.p. 160-180 ${ }^{\circ}$. The whole material was esterified in ethanol with diazoethane and the diluted product was extracted with ether. The ether was washed with dilute aqueous $\mathrm{NH}_{3}$ and water, dried $\left(\mathrm{Na}_{2} \mathrm{SO}_{4}\right)$ and evaporated. The esters formed a yellow gum weighing $352 \mathrm{mg}$. This was dissolved in benzene and separated on a column containing $\mathrm{Al}_{2} \mathrm{O}_{3}(7 \mathrm{~g}$.) as shown in Table 6. From the behaviour of this material on the column and from the reactions of fractions with $\mathrm{HCl}$, it was concluded that at least two major constituents were present. Fractions XII-XV each gave, on standing with l.p., characteristic thread-like 'gelatinous' crystals. These were collected, washed with l.p. and dried in vacuo. (Found after drying at $60-70^{\circ}$ in vacuo: Fraction XIII: C, 69.1; H, 10.7. Fraction XVI: C, 68.2; H, 10.2. $\mathrm{C}_{29} \mathrm{H}_{50} \mathrm{O}_{6}, \mathrm{H}_{2} \mathrm{O}$ requires $\mathrm{C}, 68 \cdot 0 ; \mathrm{H}, 10 \cdot 2 \%$ ).

The remainders of Fractions XII-XV were combined and this material (23.3 mg.) was hydrolysed at approx. $70^{\circ}$ for 30 min. with ethanol $(0 \cdot 2 \mathrm{ml}$.) and KOH (1 drop of $40 \%)$. After dilution with water, the clear solution was acidified 


\section{Table 6. Chromatography of ethyl esters from bile salts of Varanus}

$\left(0.352 \mathrm{~g}\right.$. on $7 \mathrm{~g} . \mathrm{Al}_{2} \mathrm{O}_{3}$. In this and all other chromatograms, percentages of solvents are $\mathrm{v} / \mathrm{v}$.)

\begin{tabular}{|c|c|c|c|}
\hline Fraction & Eluant & $\begin{array}{l}\text { Vol. } \\
\text { (ml.) }\end{array}$ & $\begin{array}{l}\text { Eluate } \\
\text { Wt. (mg.) etc. }\end{array}$ \\
\hline $\mathbf{I}$ & Benzene & 30 & $\begin{array}{l}\text { 109. Oil, soluble in l.p. Gave no } \\
\text { digitonide }\end{array}$ \\
\hline II-III & Benzene & 30 & 12·7. Cholesterol \\
\hline IV & $10 \%$ Ether-benzene & 20 & 0.9 . Gum \\
\hline V & $20 \%$ Ether-benzene & 20 & Trace \\
\hline VI & $30 \%$ Ether-benzene & 20 & 2.2. Gum \\
\hline VII & $40 \%$ Ether-benzene & 40 & 1.0. Gum \\
\hline VIII & $50 \%$ Ether-benzene & 20 & 3.7. Gum \\
\hline IX-XI & Ether & 220 & 98.6. Gum. Insoluble in conc. $\mathrm{HCl}$ \\
\hline XII & Ether & 120 & 14.2. Gum, purplish colour in H-test \\
\hline XIII & Ether & 120 & 17.0. Gum, purplish colour in H-test \\
\hline XIV & Ether & 120 & 12.2. Gum, purplish colour in H-test \\
\hline $\mathbf{X V}$ & Ether & 120 & 18.0. Gum, purplish colour in H-test \\
\hline XVI & Ether & 120 & 15.2. Gum, purplish colour in H-test \\
\hline XVII & Ether & 120 & 2.0. Gum \\
\hline XVIII-XIX & Ethanol & 80 & $28 \cdot 3$ \\
\hline
\end{tabular}

Table 7. Chromatography of ethyl esters from bile salts of Indian Python $\left(0 \cdot 34\right.$ g. on 6 g. $\mathrm{Al}_{2} \mathrm{O}_{3}$.)

\begin{tabular}{|c|c|c|c|}
\hline Fraction & Eluant & $\begin{array}{l}\text { Vol. } \\
\text { (ml.) }\end{array}$ & $\begin{array}{c}\text { Eluate } \\
\text { Wt. (mg.) etc. }\end{array}$ \\
\hline $\mathbf{I}$ & Benzene & 30 & 60.0. Oil \\
\hline II & Benzene & 50 & 15.0. Gum \\
\hline III & Benzene & 50 & 61.0. Cholesterol \\
\hline IV & Benzene & 100 & 6.0. Gum \\
\hline V & $10 \%$ Ether-benzene & 200 & 5.2. Gum \\
\hline VI & $25 \%$ Ether-benzene & 50 & 1.0. Gum \\
\hline VII & $50 \%$ Ether-benzene & 50 & 5.0. Gum \\
\hline VIII & Ether & 100 & 4.0. Gum \\
\hline IX & Ether & 200 & 2.0. Gum \\
\hline $\mathrm{X}$ & $10 \%$ Ethanol-ether & 50 & 87.0. Yellow-white, H-test, negative \\
\hline $\mathbf{X I}$ & $10 \%$ Ethanol-ether & 100 & 3.0. Gum \\
\hline XII & $50 \%$ Ethanol-ether & 200 & 12.0. Gum \\
\hline XIII & Ethanol & 1350 & 46.0. Salt of an acid \\
\hline
\end{tabular}

with $\mathrm{H}_{2} \mathrm{SO}_{4}$ and saturated with $\mathrm{NaCl}$. The precipitated acid was collected after $2 \mathrm{hr}$., washed and dissolved in ethanol. Evaporation of the filtered solution left a gum which crystallized on the addition of a little ethyl acetate as groups of small white needles. Yield, $15 \mathrm{mg}$. This varanic acid had melting point about $120^{\circ}$, with effervescence; H-test, green $\rightarrow$ bluish purple. (Found, on a sample dried to constant weight at $60^{\circ}: \mathrm{C}, 67 \cdot 4 ; \mathrm{H}, 10 \cdot 2$. Equiv. (titration), 484. $\mathrm{C}_{27} \mathrm{H}_{46} \mathrm{O}_{6} \cdot \mathrm{H}_{2} \mathrm{O}$ requires $\mathrm{C}, 66 \cdot 9 ; \mathrm{H}, 9 \cdot 9 \%$; mol. wt. 484.)

Fractions IX-XI appeared to contain a second major constituent of the ester mixture and hydrolysis gave an acidic gum which formed what appeared to be a crystalline $\mathrm{K}$ salt (m.p. about $225^{\circ}$ ), but could not be obtained as a crystalline free acid or ethyl ester.

Constrictor occidentalis, Boa constrictor. Gall-bladders yielded $11.8 \mathrm{~g}$. of bile salts. $1.0 \mathrm{~g}$. of these gave $667 \mathrm{mg}$. of acids which yielded, with diazoethane, $442 \mathrm{mg}$. of ethyl esters. These were separated on a column of $\mathrm{Al}_{2} \mathrm{O}_{3}(8 \mathrm{~g}$.$) .$ Hydrolysis on the column occurred, for methanol, followed by ethanol acidified with acetic acid, was required to elute about $300 \mathrm{mg}$. of the material which then behaved as a salt. Of the remainder, a fraction $(5 \cdot 0 \mathrm{mg}$., eluted with $40 \mathrm{ml}$. benzene) gave, with ether, $1 \mathrm{mg}$. of lactonic material, m.p. 268-270 ${ }^{\circ}$ (decomp.), not depressed by pythocholic lactone.
Python molurus, Indian python. A single gall-bladder gave $7 \cdot 5 \mathrm{~g}$. brown bile salts, containing approx. $6 \% \mathrm{~S}$. Taurine, m.p. $300^{\circ}$, was isolated from the bile salts. 'Purified' bile salts (1.0 g.) on hydrolysis, gave $0.60 \mathrm{~g}$. acids. No crystals were obtained with ethyl acetate. The esters $(0.34 \mathrm{~g}$.) obtained after treatment with diazoethane were dissolved in benzene, and separated on a column containing $\mathrm{Al}_{2} \mathrm{O}_{3}(6 \mathrm{~g}$.) as shown in Table 7.

The solid from fraction $\mathrm{X}$ was crystallized from ether. It (66 mg.) then had m.p. 80-82 ; H-test, yellow-green. (Found: $\mathrm{C}, 70 \cdot 5 ; \mathrm{H}, 10 \cdot 2 . \mathrm{C}_{26} \mathrm{H}_{44} \mathrm{O}_{5}$ requires $\mathrm{C}, 71 \cdot 6, \mathrm{H}, 10 \cdot 1 \%$.) This ester was hydrolysed, at approx. $70^{\circ}$ for $20 \mathrm{~min}$., with ethanol ( $1 \mathrm{ml}$.) and KOH (1 drop of $40 \%$ ). After dilution with water, the clear solution was acidified with $\mathrm{H}_{2} \mathrm{SO}_{4}$ and saturated with $\mathrm{NaCl}$. After $3 \mathrm{hr}$. the precipitated acid was collected, washed and dissolved in ethanol. The residue after evaporation of the filtered solution was left with ethyl acetate at $0-5^{\circ}$ for some hours. The crystals (3 mg.) were collected and had m.p. 168-170 ${ }^{\circ}$, with effervescence. A second preparation of the ethyl ester of this acid, orystallized from ether-ethanol-l.p., had m.p. 95-99 ${ }^{\circ}$, with effervescence. Hydrolysis of the esters had again occurred on the column, and free acids $(0.37 \mathrm{~g}$.) were recovered from the salt eluted with methanol. This acid, crystallized from ethyl acetate, weighed $0.15 \mathrm{~g}$. and had m.p. $174-176^{\circ}$ (effervescence). An 
attempt was made to prepare pythocholic lactone from this acid: it was dissolved in $\mathrm{N}-\mathrm{NaOH}(2 \mathrm{ml}$.) and the solution acidified, while hot, with $\mathrm{H}_{2} \mathrm{SO}_{4}$; it was then heated at approx. $80^{\circ}$ for $30 \mathrm{~min}$. and left for $48 \mathrm{hr}$. The unchanged acid was recovered. On recrystallization from ethyl acetate, the acid had m.p. 181-181.5 and gave a yellow-green colour in the H-test. (Found: $\mathrm{C}, 69 \cdot 4 ; \mathrm{H}, 9 \cdot 8$. Equiv. (titration) $418,422 . \mathrm{C}_{24} \mathrm{H}_{40} \mathrm{O}_{5}$ requires $\mathrm{C}, 70 \cdot 6 ; \mathrm{H}, 10.0 \%$; mol. wt. 408.)

Pythocholic lactone was then prepared from the 'purified' bile salts. These $(0.99 \mathrm{~g}$.) were hydrolysed and, after standing with acid, yielded unconjugated material $(0 \cdot 42 \mathrm{~g}$.). This material was shaken with dilute $\mathrm{NaOH}$ and the insoluble portion collected by filtration. The precipitate was well washed with water and dissolved in ethanol, with warming. Evaporation of the filtered solution gave a brown gummy residue from which, on extraction with boiling ethyl acetate, was obtained the crystalline lactone (96 mg.), m.p. 262-264, (decomp.), not depressed by an authentic sample of pythocholic lactone from the African python.

Python sebae, African python. A single gall-bladder gave $6 \cdot 7 \mathrm{~g}$. pale-green bile salts, containing approx. $6 \%$ sulphur. 'Purified' bile salts (3.0 g.) yielded on hydrolysis $1.86 \mathrm{~g}$. of material which, after standing with acid, was mainly insoluble in ethyl acetate but readily crystallizable from ethanol. Soxhlet extraction with ethyl acetate gave a crystalline product which had m.p. 255-257 ${ }^{\circ}$ (decomp.) raised by recrystallization from ethyl acetate to $264-266^{\circ}$ (decomp.). This substance was pythocholic lactone. (Found: $\mathrm{C}, 73 \cdot 4 ; \mathrm{H}, 9 \cdot 8 . \mathrm{C}_{24} \mathrm{H}_{38} \mathrm{O}_{4}$ requires $\mathrm{C}, 73 \cdot 8 ; \mathrm{H}, 9.7 \%$.) Pythocholic lactone (10 mg.) was used for the preparation of the corresponding acid: it was added to $2 \mathrm{~N}-\mathrm{NaOH}(2 \mathrm{ml}$.) and the solution heated at approx. $80^{\circ}$ for $1 \mathrm{hr}$. The clear solution was acidified with dilute $\mathrm{H}_{2} \mathrm{SO}_{4}$, saturated with $\mathrm{NaCl}$, and left for $10 \mathrm{~min}$. The precipitated acid was then collected. Pythocholic acid was then prepared from the original bile salts: $1.0 \mathrm{~g}$. was hydrolysed, and the alkaline solution diluted, acidified with $2 \mathrm{~N}-\mathrm{H}_{2} \mathrm{SO}_{4}$, and saturated with $\mathrm{NaCl}$ : the precipitated acid was collected at once. The acid ( 0.65 g.) formed a friable mass which was well washed with water, and dried in a desiccator. The crude acid, crystallized from ethyl acetate, had m.p. $144-146^{\circ}$, with effervescence, raised by one recrystallization from ethyl acetate to $157-160^{\circ}$. The crude acid was dissolved in $\mathrm{NaOH}$ and reprecipitated with $\mathrm{H}_{2} \mathrm{SO}_{4}$.
After drying, and recrystallization from ethyl acetate, pythocholic acid had m.p. $157-160^{\circ}$ raised by two recrystallizations from ethyl acetate to 186-187 . (Found: C, 70.4; $\mathrm{H}, 10 \cdot 1$. Equiv. (titration) 401. $\mathrm{C}_{24} \mathrm{H}_{40} \mathrm{O}_{5}$ requires $\mathrm{C}, 70 \cdot 6$; $\mathrm{H}, \mathbf{1 0 . 0} \%$; mol. wt. 408.) In a preliminary note (Haslewood \& Wootton, $1950 b$ ) we referred to this acid as ' pythonic acid'. Since, however, it is apparently a substituted cholanic acid, we think that the trivial name 'pythocholic acid' is more suitable. This acid was used to prepare the lactone: it (10 mg.) was dissolved in $2 \mathrm{~N}-\mathrm{NaOH}(2 \mathrm{ml}$.), acidified with $\mathrm{H}_{2} \mathrm{SO}_{4}$, warmed to approx. $70^{\circ}$ and left $15 \mathrm{hr}$. The precipitate was collected, washed with water and dried. It was alkaliinsoluble and, crystallized from ethyl acetate, had m.p. 259-263 ${ }^{\circ}$ (decomp.), not depressed by an authentic sample of pythocholic lactone.

Boiga dendrophilus, Black and gold tree snake. One gallbladder gave $0.8 \mathrm{~g}$. dark-green bile salts, which on hydrolysis yielded acids $(0.38 \mathrm{~g}$.) which readily crystallized from ethyl acetate. Cholic acid (0.27 g.) obtained had m.p. 190-192 raised by one recrystallization from ethyl acetate to 195$196^{\circ}$. Oxidation of this gave dehydrocholic acid, m.p. 226-228 ${ }^{\circ}$ (decomp.) after two recrystallizations from dilute ethanol.

Drymarchon corais couperi, Indigo snake. A single gallbladder gave $0.42 \mathrm{~g}$. of brown bile salts which after hydrolysis yielded cholic acid (0.13 g.), m.p. 194-197 ${ }^{\circ}$. Oxidation of this gave dehydrocholic acid, m.p. 225-227 ${ }^{\circ}$ (decomp.).

Dendraspis viridis, Hallowell's green mamba. One gallbladder gave $0 \cdot 25 \mathrm{~g}$. dark-green bile salts, which yielded $0.11 \mathrm{~g}$. acids on hydrolysis. Cholic acid crystallized from these had m.p. 195-196 ${ }^{\circ}$. Ethyl dehydrocholate from this had m.p. 219-220.

Naja nivea, Yellow cobra. One gall-bladder gave $0 \cdot 45 \mathrm{~g}$. bile salts, which yielded $0.2 \mathrm{~g}$. acids on hydrolysis. Cholic acid was obtained from this as a hydrate of m.p. $135^{\circ}$, raised by one recrystallization to m.p. $178^{\circ}$ (effervescence). This material was then ethylated and oxidized; it then gave ethyl dehydrocholate, m.p. 220-222 .

Bitis gabonica, Gaboon viper. Two gall-bladders gave $4 \cdot 2 \mathrm{~g}$. pale-brown bile salts, containing approx. $5 \%$ sulphur. 'Purified' bile salts ( 1.0 g.) on hydrolysis yielded 0.62 g. acids, which with ethyl acetate gave $98 \mathrm{mg}$. of crystalline material, m.p. 130-145 ${ }^{\circ}$. The whole of the acidic material was dis-

\section{Table 8. Chromatography of ethyl esters from bile salts of Gaboon viper}

$$
\left(0 \cdot 32 \text { g. on } 3 \cdot 2 \text { g. } \mathrm{Al}_{2} \mathrm{O}_{3}\right. \text {.) }
$$

Fraction
I
II
III
IV
V
VI
VII
VIII
IX
X
XI
XII
XIII
XIV
XV
XVI
XVII

Eluant

Benzene

Benzene

Benzene

Benzene

Benzene

$20 \%$ Ether-benzene

$75 \%$ Ether-benzene

Ether

Ether

Ether

$10 \%$ Ethanol-ether

$10 \%$ Ethanol-ether

$10 \%$ Ethanol-ether

$20 \%$ Ethanol-ether

$50 \%$ Ethanol-ether

Ethanol

Ethanol

Vol.

(ml.)

30

50

50

50

50

50

100

450

100

350

100

100

250

100

100

100

1500
Wt. (mg.) etc.

20.3. Yellow oil

1.1. Gum

14.8. White solid, H-test, purple

6.6. White solid, H-test, magenta

5.6. Gum, H-test, purple

5.3. Gum

3.0. Gum

10.9. Gum

5.7. Gum, H-test, negative

8.8. Gum, H-test, negative

75.0. White solid, H-test, magenta

15.2. Crystalline, H-test, magenta

$\mathbf{7 \cdot 5}$

7.4. Crystalline

7.6. Gum

3.0. Gum

41.4. Gum 
solved in ethanol, esterified with diazoethane and extracted with ether, as described above. The esters $(0.32 \mathrm{~g}$.) were dissolved in benzene and separated on a column containing $\mathrm{Al}_{2} \mathrm{O}_{3}$ (3.2 g.) as shown in Table 8.

The ethyl ester from fraction XI crystallized from ether-l.p., had m.p. 133-136 ${ }^{\circ}$. (Found: $\mathrm{C}, 68 \cdot 8 ; \mathrm{H}, 9 \cdot 1 . \mathrm{C}_{26} \mathrm{H}_{44} \mathrm{O}_{5} \cdot \mathrm{H}_{2} \mathrm{O}$ requires $\mathrm{C}, 68.7 ; \mathrm{H}, 10.1 \%$.) This ester was then hydrolysed and the acid collected. It had m.p. 150-152 ${ }^{\circ}$; H-test, magenta. There was insufficient material for further purification, and the acid was not obtained crystalline.

Crotalus horridus, Timber rattler. One gall-bladder gave $0.25 \mathrm{~g}$. brown bile salts which, on hydrolysis, yielded acids which readily crystallized from ethyl acetate, giving cholic acid (0.144 g.) of m.p. 191-192 $2^{\circ}$, raised by two recrystallizations from ethyl acetate to $195-196^{\circ}$. Oxidation of this cholic acid gave dehydrocholic acid, m.p. 229-230 (decomp.).

Crotalus oreganus, Oregon rattler. Two gall-bladders gave $0.26 \mathrm{~g}$. yellow-brown bile salts which, after hydrolysis and working up as above, yielded cholic acid, m.p. 195-196 ${ }^{\circ}$.

Chelone midas, Green edible turtle. Five gall-bladders gave $2 \cdot 2 \mathrm{~g}$. dark-green bile salts; $0.93 \mathrm{~g}$. was hydrolysed giving $0.44 \mathrm{~g}$. acids: H-test, negative. These acids would not crystallize from ethyl acetate; they were esterified in ethanol with diazoethane. $0 \cdot 23 \mathrm{~g}$. 'Esters' were obtained and $0.11 \mathrm{~g}$. free acids recovered. The esters were dissolved in benzene and separated on a column of $\mathrm{Al}_{2} \mathrm{O}_{3}(4.0 \mathrm{~g}$.$) .$ Cholesterol (20 mg.) was eluted with benzene. An etherinsoluble gum (H-test, negative) (8.8 mg.) was eluted with $10 \%(v / v)$ ethanol-ether, and $8.3 \mathrm{mg}$. of a white solid (H-test, negative) was eluted with $50 \%(v / v)$ ethanol-ether. Hydrolysis of the esters had occurred on the column, and the remaining material was recovered as free acid from the salt eluted with methanol and then with acidified methanol. This acid could not be induced to crystallize.

Macropus ruficollis bennetti, Wallaby. Four gall-bladders gave $4.35 \mathrm{~g}$. brown bile salts. 'Purified' bile salts $(1.0 \mathrm{~g}$.) yielded on hydrolysis $0.5 \mathrm{~g}$. acids which readily crystallized from ethyl acetate, giving cholic acid $(0.16 \mathrm{~g}$.$) as a hydrate$ of m.p. $170^{\circ}$ (effervescence). Ethyl cholate prepared from this had m.p. $159-160^{\circ}$; it was oxidized to ethyl dehydrocholate, m.p. $217-219^{\circ}$.

Didelphys marsupialis virginiana, Opossum. One gallbladder gave $\mathbf{0 . 7 5} \mathrm{g}$. brown bile salts which on hydrolysis gave cholic acid of m.p. $192-195^{\circ}$, raised by recrystallization from ethyl acetate to $197-198^{\circ}$.

Erinaceus europaeus, Hedgehog. Eleven gall-bladders gave $1.1 \mathrm{~g}$. brown bile salts containing approx. $6 \% \mathrm{~S}$. Hydrolysis of $0 \cdot 6 \mathrm{~g}$. yielded $0 \cdot 3 \mathrm{~g}$. acids which readily crystallized from ethyl acetate, giving cholic acid (0.2 g.) as a hydrate of m.p. $135^{\circ}$, with effervescence. After drying and recrystallization from ethyl acetate it had m.p. 193-195 ${ }^{\circ}$. Oxidation of this gave dehydrocholic acid, m.p. 228-230 (decomp.) after recrystallization from dilute ethanol.

Papio anubis, Olive baboon. One gall-bladder gave $0.9 \mathrm{~g}$. yellow bile salts containing approx. $4 \% \mathrm{~S}$. Hydrolysis of $0.3 \mathrm{~g}$. yielded $0.16 \mathrm{~g}$. acids, from which cholic acid $(96 \mathrm{mg}$.) was isolated in the form of a hydrate of m.p. 175-176 (effervescence), raised by drying and recrystallization from ethyl acetate, to $193-195^{\circ}$. This was oxidized to dehydrocholic acid, m.p. $225-228^{\circ}$ (decomp.) after two recrystallizations from dilute ethanol.

Macacus mulatta, Rhesus. One gall-bladder gave $0 \cdot 7 \mathrm{~g}$. brown bile salts containing approx. $7 \% \mathrm{~S}$. Hydrolysis of this gave $0.27 \mathrm{~g}$. acids, from which cholic acid was isolated; it had m.p. $185-187^{\circ}$, raised by one recrystallization from ethyl acetate to $192-195^{\circ}$. This was oxidized to give dehydrocholic acid, m.p. 228-230 (decomp.) after recrystallization from dilute ethanol.

Mandrillus leucophaeus, Mandrill. One gall-bladder gave $0.44 \mathrm{~g}$. brown bile salts which on hydrolysis yielded acids $\left(0.25 \mathrm{~g}\right.$.) from which was isolated cholic acid of m.p. $175-177^{\circ}$, raised by one recrystallization from ethyl acetate to $193-195^{\circ}$. Oxidation of this gave dehydrocholic acid of m.p. 228-229 (decomp.) after one recrystallization from dilute ethanol.

Pan pigmaeus, Chimpanzee. One gall-bladder gave $2 \cdot 15 \mathrm{~g}$. dark-brown bile salts, containing approx. $5 \% \mathrm{~S}$. Hydrolysis of $1.0 \mathrm{~g}$. yielded $0.55 \mathrm{~g}$. acids, from which was isolated cholic acid of m.p. $184-189^{\circ}$, raised by one recrystallization from ethyl acetate to $194-195^{\circ}$. Oxidation of this gave dehydrocholic acid of m.p. 227-228 (decomp.) after one recrystallization from dilute ethanol.

Mus musculus, Mouse. Gall-bladders from 297 animals gave $0.24 \mathrm{~g}$. bile salts which gave a positive test for $\mathrm{S}$ (qualitative). Hydrolysis of $0.22 \mathrm{~g}$. gave $0 \cdot 16 \mathrm{~g}$. acids which were dissolved in ethanol and esterified with diazoethane. The esters $(0.13 \mathrm{~g}$.), in benzene, were separated on a column containing $\mathrm{Al}_{2} \mathrm{O}_{3}(1 \cdot 3 \mathrm{~g}$.$) . Benzene (30 \mathrm{ml}$.) eluted $82 \mathrm{mg}$. of product, H-test, negative; 5 mg. more material were washed off with ether-benzene and ether. Finally, ethanol $(20 \mathrm{ml}$. gave a solid (35 mg.), crystallizing from $50 \%$ (v/v) ether-l.p. as ethyl cholate, m.p. $160-162^{\circ}$, oxidized to ethyl dehydrocholate, m.p. 217-219 .

Myocastor coypu, Nutria (Coypu) rat. Two gall-bladders gave 2.82 g. pale-green bile salts containing approx. $4 \% \mathrm{~S}$. $1.0 \mathrm{~g}$. of the 'orude' bile salts was hydrolysed, yielding $0.46 \mathrm{~g}$. acids. Gelatinous crystals of nutriacholic acid were obtained with ethyl acetate. This had m.p. 178-184 ${ }^{\circ}$, raised by one recrystallization from ethyl acetate to $193-195^{\circ}$, H-test, negative. Ethyl nutriacholate was prepared; it had m.p. 185-187.

Balaenoptera physalus, Fin whale. About $3000 \mathrm{ml}$. (diluted) bile containing approx. $4 \cdot 8 \mathrm{~g}$. bile salts $/ 100 \mathrm{ml}$. was obtained from a single specimen. Cholesterol (0.15 g.) was isolated from the neutral material. Hydrolysis of $10 \mathrm{~g}$. 'purified' bile salts gave $3 \cdot 3 \mathrm{~g}$. cholic acid, m.p. $191^{\circ}$. This was ethylated as described, giving ethyl cholate, m.p. $157-159^{\circ}$. The cholic acid was also oxidized, to give dehydrocholic acid, m.p. $230^{\circ}$ (decomp.). The residue from the ethyl acetate mother liquors, on treatment with glacial acetic acid, yielded deoxycholic acid-acetic acid (28.3 mg.) of m.p. $131-135^{\circ}$, raised by one recrystallization from glacial acetic acid to 137- $140^{\circ}$, not depressed by an authentic sample of deoxycholic-acetic acid complex. Taurine was isolated from the 'purified' bile salts; it had m.p. $298^{\circ}$, not depressed by an authentic sample from ox bile.

Balaenoptera sibbaldi, Blue whale. Dark-green bile (25 ml.) gave $0.99 \mathrm{~g}$. 'crude' bile salts, which yielded $0.4 \mathrm{~g}$. acids. Cholic acid $\left(0.2\right.$ g., m.p. $\left.196-198^{\circ}\right)$ was crystallized from this. Oxidation of the cholic acid gave dehydrocholic acid m.p. 225-228 (decomp.) after two recrystallizations from dilute ethanol.

Canis dukhunensis, Indian wild dog. One gall-bladder gave $3.2 \mathrm{~g}$. light-brown bile salts which gave a positive (qualitative) test for S. 'Purified' bile salts ( 1.0 g.) gave, on hydrolysis, $0.56 \mathrm{~g}$. acids, from which crystalline cholic acid was obtained as a hydrate, m.p. $135-139^{\circ}$ (effervescence). Oxidation of this gave dehydrocholic acid of m.p. 227-230 (decomp.) after two recrystallizations from dilute ethanol. 
Ursus americanus, American black bear. One gall-bladder gave $9 \cdot 7 \mathrm{~g}$. brown bile salts, containing $\mathrm{S}$ (qualitative test). 'Purified' bile salts $(1.0 \mathrm{~g}$.) yielded on hydrolysis $0.56 \mathrm{~g}$. acids, from which cholic acid $(0.24 \mathrm{~g}$.) was isolated; it had m.p. $182-185^{\circ}$, raised by one recrystallization from ethyl acetate to $192-195^{\circ}$. This was oxidized to give dehydrocholic acid, m.p. 225-228 ${ }^{\circ}$ (decomp.). Deoxycholic acid was not obtained on treatment of the residue from ethyl acetate mother liquors with acetic acid. In an attempt to isolate ursodeoxycholic acid, $4 \cdot 5 \mathrm{~g}$. bile salts were hydrolysed, giving $2 \cdot 71 \mathrm{~g}$. acids, from which cholic acid $(1 \cdot 4 \mathrm{~g}$.) was crystallized. The residue $(1.1 \mathrm{~g}$.) was ethylated as described, and the esters $(0.86 \mathrm{~g}$.) dissolved in benzene and separated on a column containing $\mathrm{Al}_{2} \mathrm{O}_{8}(17 \cdot 0 \mathrm{~g}$.). Benzene (100 ml.) eluted $367 \mathrm{mg}$. of material, including cholesterol. Ether-benzene yielded a gum (40 mg., H-test, negative) and ether and ethanol-ether gave mainly ethyl cholate. No crystals from the ether-benzene product were obtained with ethyl acetate or acetic acid.

Helarctos malayanus, Malay bear. One gall-bladder gave $5.0 \mathrm{~g}$. brown bile salts containing approx. $4 \% \mathrm{~S}$. On hydrolysis, $1.0 \mathrm{~g}$. yielded $0.59 \mathrm{~g}$. acids, from which cholic acid $\left(0 \cdot 21 \mathrm{~g}\right.$. of m.p. $\left.185-187^{\circ}\right)$ was crystallized. This was oxidized and gave dehydrocholic acid of m.p. $227-229^{\circ}$ (decomp.) after one recrystallization from dilute ethanol.

Thalarctos maritimus, Polar bear. One gall-bladder gave $16.0 \mathrm{~g}$. brown bile salts containing approx. $5 \% \mathrm{~S}$. 'Purified' bile salts $(0.9 \mathrm{~g}$.) yielded $0.57 \mathrm{~g}$. acids from which cholic acid $(0 \cdot 15 \mathrm{~g}$.) was obtained. The residue from the ethyl acetate mother liquors was treated with glacial acetic acid, and crystals (possibly of a hydrocarbon) were obtained of m.p. $71^{\circ}$. The residue was then distributed between $90 \%(v / v)$ methanol-water and l.p. and the residue, after evaporation of the methanol, was left with glacial acetic acid. No deoxy- cholic acid could be crystallized. A 3.0 g. sample of 'purified' bile salts was then hydrolysed, and worked up as described above. No ursodeoxycholic acid could be crystallized from the material (92 mg.) showing a negative H-test.

Nasau nasau, Ringtailed coati. One gall-bladder gave $0.34 \mathrm{~g}$. brown bile salts containing $\mathrm{S}$ (qualitative test). On hydrolysis $0 \cdot 17 \mathrm{~g}$. acids were obtained, from which cholic acid (70 mg. of m.p. $185-187^{\circ}$ ) was crystallized. Oxidation of this gave dehydrocholic acid of m.p. 228-230 ${ }^{\circ}$ (decomp.) after two recrystallizations from dilute ethanol.

Acinonyx jubatus, Cheetah. One gall-bladder gave 6.0 g. brown bile salts containing approx. $5 \% \mathrm{~S}$. 'Purified' bile salts $(1.9 \mathrm{~g}$.) on hydrolysis yielded cholic acid $(0.8 \mathrm{~g}$.$) of$ m.p. $196^{\circ}$. This was oxidized to give dehydrocholic acid, m.p. 229-232 (decomp.).

Crossarchus obscurus, Kusimanse. One gall-bladder gave $0 \cdot 15 \mathrm{~g}$. pale-green bile salts which on hydrolysis yielded $83 \mathrm{mg}$. acids. Cholic acid crystallized from this had m.p. $189-190^{\circ}$, raised by one recrystallization from ethyl acetate to $193-196^{\circ}$. This was oxidized to give dehydrocholic acid, m.p. 228-229 (decomp.) after recrystallization.

Equus, Horse. Bile (52 ml.) collected as described on p. 585 , gave $1.206 \mathrm{~g}$. crude bile salts; $500 \mathrm{mg}$. of these on hydrolysis yielded $134 \mathrm{mg}$. of acidic gum which gave no crystalline material with ethyl acetate or acetic acid. The gum was esterified with diazoethane, and the gummy neutral material obtained was purified on columns as shown in Table 9. Fractions XX and XXI (column 4) readily gave crystals with l.p.-ether : these were collected and washed with l.p., yield 1.5 mg., m.p. 151-155 ${ }^{\circ}$ H-test, very intense blue. Recrystallized from l.p.-benzene, this ethyl cholate had m.p. $154-156^{\circ}$.

The bulk of the material, namely that in column 2 , fraction I (97.4 mg.), was acetylated in pyridine $(1 \mathrm{ml}$.$) with$

\section{Table 9. Chromatography of ethyl esters from bile salts of horse}

(Approx. $130 \mathrm{mg}$. on $1 \mathrm{~g}$. $\mathrm{Al}_{2} \mathrm{O}_{3}$ for column 1.)

\begin{tabular}{|c|c|c|c|}
\hline Fraction & EJuant & $\begin{array}{l}\text { Vol. } \\
\text { (ml.) }\end{array}$ & Wt. (mg.), etc. \\
\hline & $\begin{array}{l}\text { Benzene } \\
\text { Ethanol }\end{array}$ & $\begin{array}{l}50 \\
50\end{array}$ & $\begin{array}{l}\text { Most of material } \\
17 \cdot 8 \text {. Partially crystallize }\end{array}$ \\
\hline & \multicolumn{3}{|c|}{ Column 2 ( $1 \mathrm{~g} \cdot \mathrm{Al}_{2} \mathrm{O}_{2}$ used for column 1 , fraction $\left.\mathrm{I}\right)$} \\
\hline & $\begin{array}{l}40 \% \text { Benzene-l.p. } \\
\text { Benzene }\end{array}$ & $\begin{array}{l}50 \\
50\end{array}$ & $\begin{array}{l}\text { 97.4. Brown gum } \\
4 \cdot 4\end{array}$ \\
\hline \multicolumn{4}{|c|}{ Column $3\left(0 \cdot 2 \mathrm{~g} . \mathrm{Al}_{2} \mathrm{O}_{3}\right.$ for column 1 , fraction II) } \\
\hline & $\begin{array}{l}\text { Benzene } \\
\text { Benzene } \\
\text { Ether }\end{array}$ & $\begin{array}{l}50 \\
50 \\
50\end{array}$ & $\begin{array}{l}\text { 12.5. Partly crystallized } \\
\text { Trace } \\
6 \cdot 1 \text {. Gum }\end{array}$ \\
\hline
\end{tabular}

I-V

VI and VII

VIII-XI

XII and XIII

$\mathrm{XIV}$ and $\mathrm{XV}$

XVI

XVII

XVIII

XIX

$\mathrm{XX}$

XXI

XXIII-XXVI
Benzene

Column 2 ( $1 \mathrm{~g} . \mathrm{Al}_{2} \mathrm{O}_{2}$ used for column 1, fraction I)

Column 4 ( $1 \mathrm{~g} . \mathrm{Al}_{2} \mathrm{O}_{3}$ for column 3, fraction I)

$33 \%$ L.p.-benzene

$50 \%$ L.p.-benzene

$60 \%$ L.p.-benzene

10 each 70 and $80 \%$ l.p.-benzene

Benzene

$10 \%$ Ether-benzene

$20 \%$ Ether-benzene

$20 \%$ Ether-benzene

$20 \%$ Ether-benzene

$20 \%$ Ether-benzene

$20 \%$ Ether-benzene

$50 \%$ Benzene, then ether, finally

acetone

$\begin{array}{cl}65 & 3 \cdot 4 . \text { Gum } \\ 50 & \text { Trace } \\ 150 & \text { Trace } \\ & \text { Trace } \\ 75 & 0 \cdot 8 \\ 20 & \text { Trace } \\ 20 & \text { Trace } \\ 20 & 1 \cdot 8 . \text { Partly crystallized } \\ 40 & 2 \cdot 6 . \text { Partly crystallized } \\ 40 & 2 \cdot 9 . \text { Partly crystallized } \\ 40 & 0 \cdot 8 . \text { Partly crystallized } \\ & \text { Traces }\end{array}$


acetic anhydride $\left(1 \mathrm{ml}\right.$.) at approx. $100^{\circ}$ for $5.5 \mathrm{hr}$. The oily acetyl derivative was extracted with ether from the diluted cooled mixture and the ether was washed with water, dil. $\mathrm{HCl}$, dil. $\mathrm{NH}_{3}$, water, dried $\left(\mathrm{Na}_{2} \mathrm{SO}_{4}\right)$ and evaporated. The residue (103 mg.) was separated into three fractions on a column and each fraction was ' seeded' with crystalline ethyl $3 \alpha: 7 \alpha$-diacetoxycholanate and ethyl $3 \alpha: 6 \alpha$-diacetoxycholanate but without result. After hydrolysis, the acidic material (70 mg.) would not crystallize as ether-deoxycholic acid. It was converted into a mixture of 3:5-dinitrobenzoyl derivatives in the usual way, and the product was esterified with diazoethane and separated on a column of $\mathrm{Al}_{2} \mathrm{O}_{3}$, but without the detection of more than traces of crystalline material. The chief ester fraction from horse bile was clearly, therefore, a complex mixture very readily eluted from $\mathrm{Al}_{2} \mathrm{O}_{3}$.

Sus, Gallstone of pig. A gallstone from a domestic pig filled the whole of the gall-bladder, which appeared no longer to contain bile: the stone was ovoid and weighed (wet) $98 \mathrm{~g}$.; it consisted of concentric layers, as described by Schenck (1938) and a small amount of what appeared to be bilirubin occupied the centre. Powdered gallstone (10 g.) was analysed by the method of Schoenheimer \& Johnston (1937) and by conventional methods, with the following results:
Ether-soluble neutral fraction KOH-soluble, water-insoluble acids Amorphous insoluble material $\mathrm{Ca}$ Water

$4 \cdot 900$ $0 \cdot 510$ $0 \cdot 230$ $4 \cdot 260$

$10 \cdot 077$

Total white needles, of (probably) ethyl $3 \beta: 6 \alpha$-diacetoxycholanate, which had m.p. 109-111 ${ }^{\circ}$, depressed by ethyl $3 \alpha: 7 \alpha$-diacetoxycholanate. (Found: $\mathrm{C}, 73 \cdot 0 ; \mathrm{H}, 9 \cdot 4 . \mathrm{C}_{30} \mathrm{H}_{48} \mathrm{O}_{6}$ requires C, $72.9 ; \mathrm{H}, 9.7 \%$.) No crystalline ester which apparently differed from this could be isolated from any other fraction even after further chromatography, except for a very little high-melting material which may have represented partially hydrolysed acetyl derivatives. The above substance (21 mg.) was heated with ethanol $(0.4 \mathrm{ml}$.) and $5 \mathrm{~N}-\mathrm{NaOH}(1$ drop) at approx. $70^{\circ}$ for $0.5 \mathrm{hr}$. The resulting acid, precipitated with dilute $\mathrm{H}_{2} \mathrm{SO}_{4}$, was collected, washed with water and crystallized from water-ethanol three times, finally appearing as white needles, m.p. 190-191 ${ }^{\circ}$, depressed by hyodeoxycholic acid (m.p. $196-197^{\circ}$ ) to $163-179^{\circ}$. The properties of this substance correspond with those of ' $\beta$ '-hyodeoxycholic acid

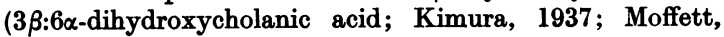
Stafford, Linsk \& Hoehn, 1946; Moffatt, 1947). Thus neither ' $\alpha$ '-hyodeoxycholic acid nor chenodeoxycholic acid was detected in the gallstone.

Phacochoerus aethiopicus, Wart hog. One gall-bladder gave $1.6 \mathrm{~g}$. light-brown bile salts from which $\mathrm{S}$ was absent. 'Purified' bile salts $(0.5 \mathrm{~g}$.) yielded on hydrolysis, $0 \cdot 24 \mathrm{~g}$. acids. Cholic acid was crystallized from this as a hydrate, m.p. $175^{\circ}$ (effervescence). $25 \mathrm{mg}$. of this hydrate were dissolved in ethanol, ethylated with diazoethane and extracted as described; the esters ( $15 \mathrm{mg}$.) were separated on a column containing $\mathrm{Al}_{2} \mathrm{O}_{3}(0 \cdot 15 \mathrm{~g}$.) and eluted with benzene, ether and finally ethanol. Ethyl cholate (5.4 mg., m.p. $154-156^{\circ}$ ) was eluted with ether and crystallized from ether1.p.

Taurotragus oryx, Eland. One gall-bladder (from a newborn animal) gave $0 \cdot 24 \mathrm{~g}$. yellow bile salts, which yielded on hydrolysis $0 \cdot 17 \mathrm{~g}$. acids. Cholic acid, crystallized from this, had m.p. $185-189^{\circ}$, raised by two recrystallizations from ethyl acetate to $194-196^{\circ}$.

\section{Preparation of reference compounds}

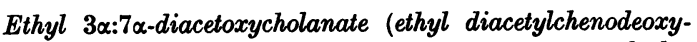
cholate). Chenodeoxycholic acid (25 mg.), prepared by 'crystallization' of the hydrolysed bile salts from hen bile, was esterified with diazoethane to give the ethyl ester (29 mg.). The gummy product was acetylated with acetic anhydride $\left(0.5 \mathrm{ml}\right.$.) in pyridine $\left(0.5 \mathrm{ml}\right.$.) for $4 \mathrm{hr}$. at $100^{\circ}$. Dilution of the cooled product with aqueous $\mathrm{HCl}$ gave a gummy precipitate, which, after 2 days, was washed with water and dissolved in ether. Evaporation of the filtered ethereal solution left a residue which, dissolved in a little benzene followed by excess l.p., was poured on to a column of $\mathrm{Al}_{2} \mathrm{O}_{3}$ (0.5 g.). The column was washed with l.p. (80 ml.) evaporation of which then left a residue which formed large

Table 10. Chromatography of acetylated ethyl esters from pig gallstone

$$
\text { (1.382 g. on } 14 \text { g. } \mathrm{Al}_{2} \mathrm{O}_{3} \text {.) }
$$

Fraction
I
II
III
IV
V
VI
VII and VIII
IX
$\mathrm{X}$

Eluant

About $100 \mathrm{ml}$. l.p.

$10 \%$ Benzene-l.p.

$10 \%$ Benzene-1.p.

$10 \%$ Benzene-l.p.

Benzene

Benzene

Benzene

Ether

Ethanol
Vol.

(ml.)

200

150

100

100

300

100

50
Wt. (g.), etc.

0.477. Gum

0.338. Gum

0.034. Crystallized

0.017. Crystallized

$0 \cdot 178$. Crystallized

$0 \cdot 029$. Crystallized

0.098 . Crystallized

$0 \cdot 028$. Crystallized

0.031. Crystallized 
colourless stout prisms from a little fresh l.p. Yield, $12 \mathrm{mg}$. This ethyl $3 \alpha: 7 \alpha$-diacetoxycholanate had m.p. 104-105 . (Found: C, 71.7; $\mathrm{H}, 9.8 . \mathrm{C}_{30} \mathrm{H}_{48} \mathrm{O}_{6}$ requires $\mathrm{C}, 71.5 ; \mathrm{H}$, 9.5\%.)

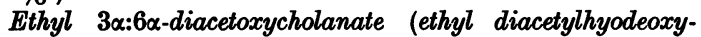
cholate). Hyodeoxycholic acid (15 mg., m.p. 196-197 ${ }^{\circ}$ was esterified and acetylated and the product purified as described above. The final ethyl $3 \alpha: 6 \alpha$-diacetoxycholanate formed long white needles from l.p. Yield, $6 \mathrm{mg}$.; m.p. 99$100^{\circ}$. (Found: $\mathrm{C}, 71 \cdot 9 ; \mathrm{H}, \mathbf{9 \cdot 6} . \mathrm{C}_{30} \mathrm{H}_{48} \mathrm{O}_{6}$ requires $\mathrm{C}, 71 \cdot 5$; H, $9.5 \%$.)

\section{RESULTS AND DISCUSSION}

The main results have been summarized in Tables 1-4. A new bile acid, pythocholic acid, has been obtained only from the bile of three species of Boidae examined, and other new crystalline biliary constituents have been isolated from frogs (one species), lizards (one species) and snakes (one species). Nutriacholic acid has been confirmed in the bile of Myocastor coypu.

A pig gallstone is shown for the first time to contain a normal constituent ( $\beta$-hyodeoxycholic acid) of pig bile.

It appears possible to formulate the following generalizations, as working hypotheses, from the information at present available about the species distribution of different kinds of bile salts.

1. Examples of the groups of vertebrates commonly recognized as being evolutionarily more primitive have $\mathrm{C}_{27}$-alcohols, conjugated with sulphate, or (possibly) $\mathbf{C}_{27}$-acids conjugated probably mainly with taurine.

2. The more 'modern' types have $\mathrm{C}_{24}$-acids, conjugated with taurine or glycine. The commonest (most widely distributed) bile salt is taurocholate and, in mammals at least, this is frequently accompanied by glycocholate and by greater or lesser amounts of conjugated deoxycholic acid. Glycoacids are apparently found only in mammalia.

3. Certain species, or small groups of related species, have (not necessarily as chief constituent) unique bile salts; on Darwin's (1859) conception of species evolution, this is to be expected. Known examples of such species are the seals and walruses, pig, nutria rat and, as we have shown, three species of Boidae among the snakes. It might be expected that 'uniqueness' of bile salts will be found to be most common amongst the more 'primitive' species. 'Uniqueness' of a different type is to be found in species such as the rabbit which has almost solely a common $\mathrm{C}_{24}$-acid (deoxycholic), but apparently conjugated only with glycine.

4. The nature of bile salts cannot, at present, be correlated in any way with the diet or other easily variable factors; it appears to be a quite characteristic property of the species.

Such generalizations may have to be modified or discarded as further information is obtained; there are very large unexplored fields in all classes of vertebrates.

It is unfortunate that many of the earlier conclusions about the chemical nature of bile steroids are not based on acceptable experimental evidence. Thus it has often been stated that a bile contains chenodeoxycholic acid when in fact all that has been shown is that an isolated bile acid mixture does not readily yield crystals of cholic acid or some complex of deoxycholic acid. Chenodeoxycholic acid is not easy to identify: few crystalline derivatives suitable for characterization are known to us.

Claims for proof of the occurrence of (conjugated) cholic acid in a bile are often based on certain colour reactions, such as the Hammarsten test, which are given by this acid. We have prepared acidic and even semi-crystalline substances from biles which give strongly positive responses to this test, but from which we were quite unable to isolate the acid or any identifiable derivative of it. For this reason, we feel that no claim for the demonstration of cholic acid can be allowed unless such characteristic compounds have been obtained. It appears to us to be particularly important to investigate carefully any case in which cholic acid or any other $\mathrm{C}_{24}$-acid may be thought to occur together with a $\mathrm{C}_{27}$-acid or $\mathrm{C}_{27}$ alcohol. Such a case, for example, was reported by Ohta (1939a) for a shark.

The position of ursodeoxycholic ( $3 \alpha$ :7 $\beta$-dihydroxycholanic) acid is obscure. It was first described by Hammarsten (1902) as occurring in the bile of the Polar bear, but no crystalline substance was isolated. Zumbutsch (1902) investigated the bile of the Isabella bear, Ursus arctos isabellinus, in order to compare it with Polar bear bile, but he does not mention ursodeoxycholic acid. From a Japanese bear, probably Ursus japonicus, Shoda (1927) obtained tauro-ursodeoxycholic acid, and Miyazi (1937) glyco-ursodeoxycholic acid. Cholic and chenodeoxycholic acid were also found in the bile. We have been unable to isolate any crystalline bile acid other than cholic acid from the Polar bear, the Malay bear and the American black bear. We can hardly commit ourselves to an opinion, on the available evidence, as to whether ursodeoxycholic acid is a characteristic acid of bear bile; however, there seems to be little doubt that cholic acid is the main constituent. Ursodeoxycholic acid in small amounts could probably have arisen by bacterial action in the intestine, from chenodeoxycholic acid.

The very interesting work on toad bile (summarized by Fieser \& Fieser, 1949), and on the bile of Amyda japonica (see Sobotka, 1937), and Emys orbicularis (Kim, 1939), certainly ought to be repeated. The published accounts (Kurauti \& Kazuno, 1939; Mabuti, 1941 $a$ ) of a chemical investigation of the bile of Rana catesbiana contain a number of entirely unjustified assumptions. 


\section{SUMMARY}

1. Improved methods of isolating crystalline material from small amounts of bile have been worked out and applied to the bile of species whose bile salts have not, to our knowledge, been previously examined.

2. New crystalline compounds have been isolated from the bile of frogs (one species), lizards (one species), and snakes (four species). Indications of other crystalline biliary constituents were obtained.

3. A new bile acid, pythocholic acid, $\mathrm{C}_{24} \mathrm{H}_{40} \mathrm{O}_{5}$, is thought to be probably characteristic of the bile of three species of Boidae; it forms the main constituent of the bile of the African python.

4. The presence of nutriacholic acid as the main bile acid of Myocastor coypu has been confirmed.
5. We have not been able to substantiate the existence of ursodeoxycholic acid (3 $\alpha: 7 \beta$-dihydroxycholanic acid) as characteristic of bear bile.

We offer our gratitude and thanks to the following, without whose generous help in the collection of bile this work could not have been undertaken: Mr A. Baker (pig gallstone), Commander Buckle, R.N. (Blue whale), Dr M. Begg and 'Discovery' Investigations (Fin whale), Mr D. H. Gadd (frog), Dr W. E. Kershaw (several monkeys), Mr H. D. Mills and the Royal Veterinary College and Hospital, London (horse), Dr R. E. Rewell, Mr W. E. Lawrence, and the Zoological Society of London (many species), Mr G. E. E. Webster (Green turtle), Mr C. Tennant Williams (Nutria rat), Dr S. W. F. Underhill (mouse), Mr R. S. Wimpenny and the Ministry of Agriculture and Fisheries (cod, plaice), Miss M. E. Wood (hedgehog).

We also gratefully acknowledge a grant from the Medical Research Council to one of us (V.W.) and for expenses.

\section{REFERENCES}

Beck, F. (1940). Proc. Soc. exp. Biol., N.Y., 43, 603.

Darwin, C. (1859). The Origin of Species. London: John Murray.

Deulofeu, V. (1934). Hoppe-Seyl. Z. 229, 157.

Fieser, L. F. \& Fieser, M. (1949). Natural Products related to Phenanthrene, 3rd ed. New York: Reinhold.

Hammarsten, O. (1901). Hoppe-Seyl. Z. 32, 435.

Hammarsten, O. (1902). Hoppe-Seyl. Z. 36, 525.

Hammarsten, O. (1904a). Hoppe-Seyl. Z. 43, 109.

Hammarsten, O. (1904b). Hoppe-Seyl. Z. 43, 127.

Haslewood, G. A. D. (1943). Biochem. J. 37, 109.

Haslewood, G. A. D. \& Wootton, V. (1950). Biochem. J. 46, $x$.

Imamura, H. (1940). J. Biochem., Tokyo, 31, 21.

Isaka, H. \& Azato, H. (1940). J. Biochem., Tokyo, 32, 241.

Ishino, N. (1938). J. Biochem., Tokyo, 28, 133.

Josephson, B. (1933). Biochem. Z. 263, 428.

Kihara, Y. (1938). J. Biochem., Tokyo, 27, 363.

Kim, C. H. (1939). J. Biochem., Tokyo, 30, 247.

Kim, C. H., Sihn, T. S. \& Takahashi, K. (1939). J. Biochem., Tolyyo, 29, 35.

Kimura, T. (1937). J. Biochem., Tokyo, 26, 327.

Kishi, S. (1936). Hoppe-Seyl. Z. 238, 210.

Kurauti, Y. \& Kazuno, T. (1939). Hoppe-Seyl. Z. 262, 53.

Mabuti, H. (1941 a). J. Biochem., Tokyo, 33, 117.

Mabuti, H. (1941 b). J. Biochem., Tokyo, 33, 143.

Mills, H. D. (1949). Vet. Rec. 61, 418.

Miyazi, S. (1937). Hoppe-Seyl. Z. 250, 34.

Moffatt, J. S. (1947). J. chem. Soc. p. 812.

Moffett, R., Stafford, J., Linsk, J. \& Hoehn, W. (1946). J. Amer. chem. Soc. 68, 185.

Mori, T. (1938). J. Biochem., Tokyo, 28, 161.
Mori, T. \& Kimura, T. (1938). J. Biochem., Tokyo, 27, 381. Neseni, R. (1937). Arch. wiss. prakt. Tierheilk. 72, 10.

Ohta, K. (1939a). J. Biochem., Tokyo, 29, 241.

Ohta, K. (1939b). Hoppe-Seyl. Z. 259, 53.

Ohta, K. (1939c). J. Biochem., Tokyo, 29, 31.

Oikawa, S. (1925). J. Biochem., Tokyo, 5, 63.

Okamura, S. \& Okamura, T. (1930). Hoppe-Seyl. Z. 188, 11.

Reindel, F. \& Niederländer, K. (1935). Ber. dtsch. chem. Ges. 68, 1969.

Saba, G. (1939). J. Biochem., Tokyo, 30, 55.

Schenck, N. (1938). Hoppe-Seyl. Z. 256, 159.

Schoenheimer, R. \& Johnston, C. (1937). J. biol. Chem. 120, 499.

Sedgwick, A. (1905). A Student's Textbook of Zoology. London: Swan and Sonnenschein.

Shibuya, S. \& Miki, T. (1932). Hoppe-Seyl. Z. 206, 279.

Shoda, M. (1927). J. Biochem., Tokyo, 7, 505.

Simpson, G. (1945). Bull. Amer. Mus. nat. Hist. 85.

Smith, M. (1927). List of Vertebrated Animals Exhibited by the Zoological Society of London. Vol. II: Amphibia and Reptiles.

Sobotka, H. (1937). Physiological Chemistry of the Bile. London: Baillière, Tindall and Cox.

Sobotka, H. \& Bloch, E. (1943). Ann. Rev. Biochem. 12, 45.

Takata, M. (1927). Jap. J. med. Sci. (Biochem. II), 1, 235.

Tanaka, K. (1932). Hoppe-Seyl. Z. 213, 199.

Tukamoto, M. \& Kataoka, Y.(1940). J. Biochem., Tokyo, 32, 473.

White, S. M. (1929). Biochem. J. 28, 1163.

Windaus, A. \& Van Schoor, A. (1928). Hoppe-Seyl. Z. 173, 312.

Zumbutsch, L. (1902). Hoppe-Seyl. Z. 35, 426. 